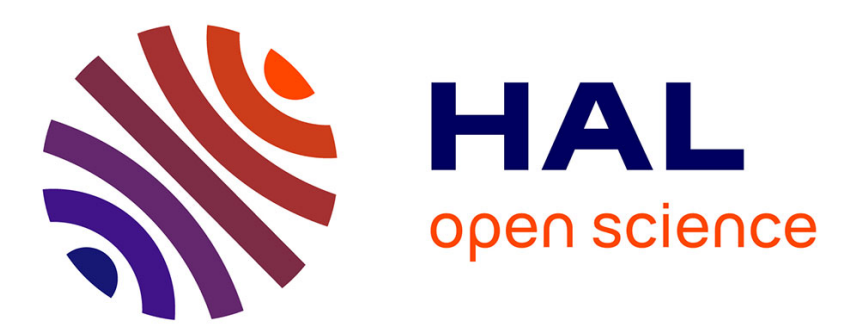

\title{
Modelling canopy fuel variables in Pinus pinaster Ait. and Pinus radiata D. Don stands in northwestern Spain
} Ibán Gómez-Vázquez, Felipe Crecente-Campo, Ulises Diéguez-Aranda, Fernando Castedo-Dorado

\section{- To cite this version:}

Ibán Gómez-Vázquez, Felipe Crecente-Campo, Ulises Diéguez-Aranda, Fernando Castedo-Dorado. Modelling canopy fuel variables in Pinus pinaster Ait. and Pinus radiata D. Don stands in northwestern Spain. Annals of Forest Science, 2013, 70 (2), pp.161-172. 10.1007/s13595-012-0245-9 hal-01201465

\section{HAL Id: hal-01201465 \\ https://hal.science/hal-01201465}

Submitted on 17 Sep 2015

HAL is a multi-disciplinary open access archive for the deposit and dissemination of scientific research documents, whether they are published or not. The documents may come from teaching and research institutions in France or abroad, or from public or private research centers.
L'archive ouverte pluridisciplinaire HAL, est destinée au dépôt et à la diffusion de documents scientifiques de niveau recherche, publiés ou non, émanant des établissements d'enseignement et de recherche français ou étrangers, des laboratoires publics ou privés. 


\title{
Modelling canopy fuel variables in Pinus pinaster Ait. and Pinus radiata D. Don stands in northwestern Spain
}

\author{
Ibán Gómez-Vázquez • Felipe Crecente-Campo • \\ Ulises Diéguez-Aranda • Fernando Castedo-Dorado
}

Received: 11 April 2012 / Accepted: 24 September 2012 /Published online: 30 October 2012

(C) INRA and Springer-Verlag France 2012

\begin{abstract}
- Context The fuel complex variables canopy bulk density and canopy base height are often used to determine crown fire initiation and spread. Direct measurement of these variables is impractical, and they must be estimated indirectly. - Aims The objectives of the present study were to model the vertical profile of available crown fuel in maritime and radiata pine stands in NW Spain, using data from destructively sampled trees; to compare the values of the canopy fuel variables estimated by two different methods and to estimate these variables from common stand descriptors.
\end{abstract}

\section{Handling Editor: Eric Rigolot}

Contribution of the co-authors Iban Gómez-Vázquez analysed the data and wrote the manuscript.

Felipe Crecente-Campo collected the data, provided technical assistance in model fitting and supervised the writing of the manuscript.

Ulises Diéguez-Aranda provided part of the experimental data and revised the text.

Fernando Castedo-Dorado developed the experimental design, coordinated the research project and supervised the work.

I. Gómez-Vázquez • F. Crecente-Campo • U. Diéguez-Aranda

Departamento de Ingeniería Agroforestal,

Escuela Politécnica Superior. C/Benigno Ledo,

Universidad de Santiago de Compostela,

Campus Universitario,

27002 Lugo, Spain

I. Gómez-Vázquez

e-mail: iban.gomez@usc.es

F. Crecente-Campo

e-mail: felipe.crecente@usc.es

U. Diéguez-Aranda

e-mail: ulises.dieguez@usc.es

F. Castedo-Dorado $(\square)$

Departamento de Ingeniería y Ciencias Agrarias,

Escuela Superior y Técnica de Ingeniería Agraria,

Universidad de León,

Avda. de Astorga s/n,

24400 Ponferrada, León, Spain

e-mail: fcasd@unileon.es
- Methods Systems of equations were fitted simultaneously to address the inherent correlations between available crown fuel components and between the canopy fuel variables. Heteroscedasticity and autocorrelation were also taken into account in the fitting process, where necessary.

- Results The values of the canopy fuel variables varied greatly depending on the estimation method used. Models for predicting the variables at stand level explained a high percentage of the observed variability. Crowning is more likely in maritime pine than in radiata pine stands.

- Conclusions Although the approach used in this study provides a realistic depiction of the vertical distribution of crown fuel, it departs from the requirements of Van Wagner's model. The method used to estimate canopy fuel variables affects fire modelling results and thus the design of fuel treatment projects.

Keywords Vertical canopy fuel distribution · Canopy bulk density $\cdot$ Canopy base height $\cdot$ Maritime pine $\cdot$ Radiata pine

\section{Introduction}

Wildland fires are the most destructive type of forest disturbance in the Atlantic area of NW Spain. This limits the benefits that forest owners obtain from their investments and therefore constrains development of the forestry sector. Recent changes in land-use patterns in the region have led to the reduction or abandonment of traditional activities, such as shrub or firewood harvesting. Moreover, because of the demand for pulpwood and chipboard, silvicultural schedules often maximise yield through the maintenance of high stocking over stand development, resulting in denser stands and hence more fire prone. Maritime pine (Pinus pinaster Ait.) and radiata pine (Pinus radiata D. Don) are the first and second conifer species in terms of area covered in NW Spain. They occupy approximately 536,000 ha as dominant species, which is equivalent to approximately $25 \%$ of the total forest 
land in the region (Xunta de Galicia 2001). These fire-prone forests (especially those dominated by maritime pine) represent approximately one half of the total area burned in NW Spain in the period 1996-2005 (MMA 2006).

The extent of forest fires in Galicia in 2006 demonstrated the limited effectiveness of the firefighting measures and suggested the need for fuel management programs to reduce the severity of wildfires and to increase the weather thresholds for effective fire fighting. Crown fire behaviour initiation and spread are key elements in gauging fire behaviour potential in conifer forests and therefore must be considered in evaluating the effectiveness of fuel management treatments during fire management planning (Keyes and O'Hara 2002). As both crown fire initiation and spread models require accurate descriptions of canopy fuel complex characteristics, canopy fuel assessment is a critical point for this task.

\subsection{Background information on canopy fuel variables}

Fuel complex structural characteristics that are commonly considered to determine crown fire initiation and spread include available canopy fuel load, canopy bulk density and canopy base height (e.g. Alexander and Cruz 2011). However, the definition of these fuel structural variables varies greatly (Cruz et al. 2003; Reindhart et al. 2006). Available canopy fuel load (CFL) is the dry mass of available canopy fuel per unit ground area. Available canopy fuel is the fuel that is consumed within the flaming front of a crown fire. Van Wagner (1977) considered that live needle foliage is the main type of aerial fuel that burns in a flaming front in conifer stands, and that "little else burns except in unusually intense fires". Nevertheless, other studies have stated that other types of fine fuels, such as live and dead twigs, lichens and bark flakes may contribute significantly to the heat released in the flaming combustion zone (e.g. Agee 1996; Call and Albini 1997; Stocks et al. 2004). Canopy bulk density (CBD) describes the amount of available fuel within a unit volume of the canopy (Van Wagner 1977). It is a key variable for discriminating the type of crown fire spread regime (Van Wagner 1977) and thus for evaluating the fire hazard and how fuel treatments affect crown fire potential. Canopy base height $(\mathrm{CBH})$ is usually defined as the lowest height above the ground at which there is sufficient canopy fuel to propagate fire vertically through the canopy (Scott and Reinhardt 2001). It is therefore a measure of the proximity of canopy fuels to surface fuels (Keyser and Smith 2010) and strongly influences the likelihood of crown fire initiation.

There is no consensus about which methods should be used to estimate $\mathrm{CBD}$ and $\mathrm{CBH}$. The most widely used approaches for estimating CBD are as follows: (1) the "load over depth" method (Cruz et al. 2003), which involves dividing the available CFL by canopy depth, assuming that canopy biomass is distributed uniformly within the stand canopy (Reindhart et al. 2006; Van Wagner 1977), and (2) smoothing the vertical bulk density profile (obtained from destructively sampled trees or assuming a predetermined crown profile) by computing a running mean of variable depth (depending on authors). Canopy bulk density is estimated from the smoothed profile as the maximum value of bulk density (Scott and Reinhardt 2001).

Several authors (e.g. Cruz et al. 2003; Van Wagner 1977) have indicated that $\mathrm{CBH}$ can be calculated as the average vertical distance between the ground surface and the live canopy fuel layer. However, Scott and Reinhardt (2001) suggested considering $\mathrm{CBH}$ as the height above ground level at which there is sufficient canopy fuel to propagate fire vertically through the canopy, i.e. the height above ground level at which the bulk density reaches a specified minimum value (Sando and Wick 1972). Nonetheless, a wide range of values have been reported. For example, although Sando and Wick (1972) established CBH as the lower vertical $0.3 \mathrm{~m}$ section with bulk density greater than $0.037 \mathrm{~kg} \mathrm{~m}^{-3}$, the threshold ranges from $0.067 \mathrm{~kg} \mathrm{~m}^{-3}$ (Williams 1978) to $0.011 \mathrm{~kg} \mathrm{~m}^{-3}$ (Scott and Reindhart 2001).

It is important to note here that the former definitions for both $\mathrm{CBD}$ and $\mathrm{CBH}$ are compatible with the canopy fuel stratum characteristics used in the crown fire initiation and propagation model developed by Van Wagner (1977), whereas the definitions for $\mathrm{CBD}_{e}$ and $\mathrm{CBH}_{\mathrm{e}}$ depart from the input specifications of this model (e.g. Alexander et al. 2004; Cruz et al. 2004; Cruz and Alexander 2010, 2012).

For operational use, direct measurement of canopy fuel characteristics is impractical and therefore indirect estimation methods are required. Some tentative estimation approaches (e.g. satellite imagery, instrument-based optical techniques) have not yielded sufficiently accurate results, at least for some canopy variables (Keane et al. 2005; Reeves et al. 2009). One of the most promising and effective methods of estimating these canopy fuel metrics at stand level is the use of equations that depend on readily available stand descriptors (Cruz and Alexander 2012; Cruz et al. 2003; Ruiz-González and Álvarez-González 2011).

The objectives of the present study were as follows: (1) to model the vertical profile of available crown fuel in P. pinaster and $P$. radiata stands in NW Spain, using data obtained from destructively sampled trees; (2) to quantify and compare the range of variation in CFL, CBD and $\mathrm{CBH}$ values, using different estimation techniques; and (3) to develop allometric equations to predict these canopy fuel characteristics from stand variables that are easily measured in forest inventories.

\section{Material and methods}

\subsection{Study area}

The study was conducted in NW Spain (in the autonomic regions of Galicia and Asturias). Sampled stands were located 
throughout the area of distribution of the species in these regions and were subjectively selected to represent a wide range of site conditions. The altitude of most sites ranges between 400 and $750 \mathrm{~m}$. The climate is characterized by mild temperatures (annual average temperature, $10-14{ }^{\circ} \mathrm{C}$ ) and a slight water deficit in summer (average annual rainfall, 1,000-1,800 $\mathrm{mm}$; average annual potential evapotranspiration, $700-850 \mathrm{~mm}$; water deficit, $150-40 \mathrm{~mm}$ ). The soil parent materials are primarily acid schist and granitic rocks. The terrain is generally hilly with slopes of gradients often exceeding $15 \%$.

\subsection{Data}

The data used were obtained from two different sources. The first source of data is the destructive sampling of 204 maritime pine and 161 radiata pine trees, which were felled in the proximity of permanent sampling plots. Between 3 and 25 trees per plot were felled (after diameter stratification) to cover the pooled diameter distribution of the plot. These trees were used to estimate the available crown fuel load as a function of easily measured tree variables. Needles and twigs smaller than $0.6 \mathrm{~cm}$ in diameter were considered as the available crown fuel load because these are the fuel components usually consumed within the flaming front of a crown fire (e.g. Stocks et al. 2004).

Total tree crown biomass was weighed in the field. Representative random samples of crown biomass were taken from each tree (from the lower, middle and upper crown levels) and then further separated in the laboratory into available fuels (i.e. needles and twigs with a maximum butt diameter of $0.6 \mathrm{~cm}$ ) and the remaining fuel size classes (branches with a minimum top diameter of $0.6 \mathrm{~cm}$ ). These samples were used to determine the dry weight ratios and the dry biomass for the biomass fractions considered. The dry weights were obtained after oven-drying the samples at $65{ }^{\circ} \mathrm{C}$ for $48 \mathrm{~h}$ in a forced air oven. Twigs were cut into small pieces before drying to facilitate water removal. To assess the required drying time, at the beginning of the study, some samples were weighed twice, $12 \mathrm{~h}$ apart, until they have reached constant mass. It was found that the samples reached a stable mass after $48 \mathrm{~h}$ and did not lose any further mass after extended drying.

A subsample of these trees (79 specimens of maritime pine and 106 of radiata pine) were more intensively sampled to estimate the vertical distribution of available crown fuel load. One suppressed, one intermediate and one dominant tree were felled in each plot to represent the full range of tree sizes. Most of these trees were located in the proximity of young and highly stocked plots, which were deliberately selected because they are usually more fire prone (see, e.g. Fernandes and Rigolot 2007). After felling, the stem was cut into 1-m sections, and the total crown biomass of each section was weighed immediately. One representative branch (or two if live and dead branches appeared in the same section) from each $1-\mathrm{m}$ section was selected in the field and then further separated in the laboratory into available fuels and the remaining fuel size classes. The samples were oven-dried at $65^{\circ} \mathrm{C}$ for $48 \mathrm{~h}$ to enable calculation of the dry weight of each fraction. The total dry weight of each fraction in each $1-\mathrm{m}$ section was obtained by multiplying the total green weight obtained in the field by the proportion of each fraction in the section and the corresponding dry weight ratios. The descriptive statistics of the selected trees are shown in Table 1, in which more intensively and less intensively sampled trees are distinguished.

The second source of data is a network of 82 maritime pine and 168 radiata pine plots. Some of the of the radiata pine plots were remeasured and therefore provided a total of 363 measurements. Although the established plot network is wider, only those plots within the range of ages and stand densities of the plots in which intensively sampled trees were felled (see above) were considered. The plot size ranged from 400 to $1,400 \mathrm{~m}^{2}$, depending on stand density, to provide a minimum of 30 trees per plot. The diameter at breast height ( $d$, centimetres) was measured in each tree in each sample plot. For radiata pine and on some measuring occasions, total tree height ( $h$, metres) and height to the base of live crown $\left(h_{b l c}\right.$, metres, defined as the lower insertion point of live branches in a tree) were measured in a randomized sample of 30 trees and in an additional sample including the dominant trees (the proportion of the 100 largestdiameter trees per hectare, depending on plot size). Total tree height and $h_{b l c}$ for the remaining trees were estimated from respectively the $h-d$ model (Castedo-Dorado et al. 2006) and the crown profile model (Crecente-Campo 2008) available for this species. For maritime pine stands, $d, h$ and $h_{b l c}$ were measured in all trees in the plots. For more details on the plot network and on the sampled trees analysed, see DiéguezAranda et al. (2009).

The following stand variables were calculated for each plot-measurement combination: number of trees per hectare $(N)$, stand basal area ( $G$, square metres per hectare), quadratic mean diameter ( $d_{q}$, centimetres), average stand height ( $H_{m}$, metres) and dominant height $\left(H_{0}\right.$, metres, defined as the mean height of the 100 largest-diameter trees per hectare). Stand age $(t)$ was determined from the plantation date. Summary statistics (minimum, maximum and mean values and standard deviations) of these stand variables are shown in Table 1.

\subsection{Modelling canopy fuel profiles}

Initially, allometric equations were developed to estimate the available crown fuel load per individual tree. These 
Table 1 Summarised data from the sample of plots and trees used in the study
$N$ number of stems per hectare,

$G$ stand basal area, $d_{q}$ quadratic mean diameter, $H_{m}$ mean stand height, $H_{0}$ dominant height, $t$ age, $d$ diameter at breast height, $h$ total tree height, $w_{l}$ dry weight of needles, $w_{b 6}$ dry weight of twigs $<6 \mathrm{~mm}$

${ }^{\mathrm{a}}$ Trees sampled for total available crown fuel

${ }^{\mathrm{b}}$ Trees sampled for vertical distribution of available crown fuel

\begin{tabular}{|c|c|c|c|c|c|c|c|c|}
\hline & \multicolumn{4}{|c|}{ P. pinaster } & \multicolumn{4}{|c|}{ P. radiata } \\
\hline & Mean & Max. & Min. & SD & Mean & Max. & Min. & $\mathrm{SD}$ \\
\hline Stand variable & \multicolumn{4}{|c|}{82 inventories } & \multicolumn{4}{|c|}{363 inventories } \\
\hline$N\left(\right.$ stems $\left.\mathrm{ha}^{-1}\right)$ & 1,346 & 2,440 & 400 & 417 & 980 & 4,864 & 280 & 490 \\
\hline$G\left(\mathrm{~m}^{2} \mathrm{ha}^{-1}\right)$ & 30.5 & 68.8 & 7.8 & 10.8 & 38.1 & 87.1 & 15.3 & 10.0 \\
\hline$d_{q}(\mathrm{~cm})$ & 17.1 & 24.1 & 10.4 & 3.4 & 24.1 & 45.3 & 7.9 & 7.6 \\
\hline$H_{m}(\mathrm{~m})$ & 10.6 & 18.9 & 4.7 & 2.7 & 19.7 & 32.7 & 9.1 & 5.2 \\
\hline$H_{0}(\mathrm{~m})$ & 12.2 & 20.9 & 5.4 & 3.1 & 22.6 & 35.4 & 11.1 & 5.4 \\
\hline$t$ (years) & 18.7 & 32 & 8 & 4.8 & 24.7 & 47 & 11 & 8 \\
\hline Tree variable & \multicolumn{4}{|c|}{204 trees $^{\mathrm{a}}$} & \multicolumn{4}{|c|}{161 trees $^{\mathrm{a}}$} \\
\hline$d(\mathrm{~cm})$ & 19.0 & 49.2 & 5.44 & 10.7 & 16.9 & 40.2 & 4.80 & 7.68 \\
\hline$h(\mathrm{~m})$ & 13.2 & 23.8 & 4.05 & 4.93 & 16.8 & 32.0 & 5.40 & 5.73 \\
\hline$w_{l}(\mathrm{~kg})$ & 9.48 & 70.23 & 0.24 & 11.81 & 5.09 & 26.40 & 0.09 & 5.14 \\
\hline \multirow[t]{2}{*}{$w_{b 6}(\mathrm{~kg})$} & 1.72 & 13.73 & 0.06 & 2.08 & 3.64 & 16.83 & 0.14 & 3.39 \\
\hline & \multicolumn{4}{|c|}{79 trees $^{\mathrm{b}}$} & \multicolumn{4}{|c|}{106 trees $^{b}$} \\
\hline$d(\mathrm{~cm})$ & 12.8 & 23.1 & 4.5 & 6.1 & 15.1 & 38.5 & 4.8 & 6.5 \\
\hline$h(\mathrm{~m})$ & 10.2 & 16.6 & 4.0 & 4.9 & 15.2 & 32.0 & 5.4 & 5.2 \\
\hline$w_{l}(\mathrm{~kg})$ & 4.13 & 15.31 & 0.24 & 3.76 & 3.61 & 21.42 & 0.09 & 4.00 \\
\hline$w_{b 6}(\mathrm{~kg})$ & 1.02 & 3.67 & 0.11 & 0.74 & 2.97 & 12.88 & 0.14 & 2.89 \\
\hline$t$ (years) & 18.5 & 32 & 12 & 7.4 & 21.0 & 44 & 12 & 7.7 \\
\hline
\end{tabular}

equations relate available fuel load components to one or more easily measured individual-tree variables:

$w_{l}=\alpha_{01} \cdot x_{i 1}^{\alpha_{i 1}}+e$

$w_{b 6}=\alpha_{02} \cdot x_{i 2}^{\alpha_{i 2}}+e$

where $w_{l}$ and $w_{b 6}$ are the dry weight of needles and fine twigs, respectively; $x_{i 1}$ and $x_{i 2}$ are the potential independent variables $\left(d, h, h_{b l c},\left(h-h_{b l c}\right) / h\right) ; \alpha_{01}, \alpha_{02}, \alpha_{i 1}$ and $\alpha_{i 2}(i=1, \ldots, n)$ are the parameters to be estimated in the fitting process and $e$ is the error term.

A similar approach to that used by Alexander et al. (2004) was followed to construct the vertical profile distribution of the available crown fuel load. The ratio between the cumulative dry weight (from the crown apex) of each 1-m section and the total weight of needles $\left(R w_{l}\right)$ and fine twigs $\left(R w_{b 6}\right)$ was calculated for each intensively sampled tree. The ratio between the corresponding length along the tree of each 1-m section and $h(R h)$ was also calculated. As these variables vary between 0 and 1 , cumulative distribution functions bounded by 0 and 1 can be used to model the relationships. Preliminary analyses showed that the two-parameter logistic function was superior to the Weibull and BertalanffyRichards distribution functions, and therefore the former was selected for analysis:
$R w_{l}=1 /\left[1+\exp \left(\beta_{01}-\beta_{11} \cdot R h\right)\right]+e$

$R w_{b 6}=1 /\left[1+\exp \left(\beta_{02}-\beta_{12} \cdot R h\right)\right]+e$

where $R w_{l}$ and $R w_{b 6}$ are the cumulative fuel ratio for needles and fine twigs, respectively; $R h$ is the relative height; $\beta_{01}, \beta_{11}, \beta_{02}$, and $\beta_{12}$ are the parameters to be estimated in the fitting process and $e$ is the error term.

According to Sando and Wick (1972), the vertical canopy fuel profiles were constructed by sectioning all the trees of each plot in $0.3-\mathrm{m}$ horizontal layers from the ground to the apex of the tallest tree. The values of $R w_{l}$ and $R w_{b 6}$ were calculated from Eqs. [3] and [4], respectively, for each 1-m section. The cumulative values were then transformed into the fraction of the total dry weight per section and multiplied by the available crown fuel load $\left(w_{l}\right.$ and $w_{b 6}$ ) estimated by Eqs. [1] and [2], respectively, for each tree. The results, summed over the stem density and converted into kilogrammes per square metre, provided the vertical distribution of the available CFL per plot. "Effective" canopy bulk density $\left(\mathrm{CBD}_{\mathrm{e}}\right)$ was estimated according to the definition proposed by Scott and Reindhart (2001), i.e. the maximum $4.5 \mathrm{~m}$ running mean of the CBD vertical distribution for layers of $0.3 \mathrm{~m}$ depth, starting from the base to the top of the canopy. "Average" canopy bulk density $\left(\mathrm{CBD}_{\mathrm{a}}\right)$ was considered as the quotient between $\mathrm{CFL}$ (kilogrammes per square metre) and the average live crown length (metres). 
Correspondingly, "average" canopy base height $\left(\mathrm{CBH}_{\mathrm{a}}\right)$ was calculated as the mean value of $h_{b l c}$ observed in the sample plots. "Effective" canopy base height $\left(\mathrm{CBH}_{\mathrm{e}}\right)$ was calculated as the lowest height where a minimum canopy bulk density of $0.037 \mathrm{~kg} \mathrm{~m}^{-3}$ (Sando and Wick 1972) of available fuel is found. Although arbitrary, this threshold was selected for the following reasons: (1) it is a compromise between the maximum and minimum values reported in the literature; (2) it has been used by other authors (e.g. Hall and Burke 2006; Mitsopoulos and Dimitrakopoulos 2007) and (3) it allows direct comparisons with other studies on these species in which the same threshold was used (Hevia et al. 2011; Ruiz-González and Álvarez-González 2011; Vega et al. 2009).

All of these fuel complex descriptors are expected to be related to stand variables that can be easily measured or estimated in forest inventories. Multiplicative power functions were selected to establish the empirical relationships because they were superior to linear and exponential models also analysed (results not shown). Two systems of equations can be established, depending on whether average or effective values of $\mathrm{CBD}$ and $\mathrm{CBH}$ are considered:

$\mathrm{CFL}=\lambda_{01} \cdot X_{\mathrm{i} 1}^{\lambda_{\mathrm{i} 1}}+e$

$\mathrm{CBD}_{\mathrm{e}}=\lambda_{02} \cdot X_{\mathrm{i} 2}^{\lambda_{12}}+e$

$\mathrm{CBH}_{\mathrm{e}}=\lambda_{03} \cdot X_{\mathrm{i} 3}^{\lambda_{13}}+e$

$\mathrm{CFL}=\lambda_{04} \cdot X_{\mathrm{i} 4}^{\lambda_{\mathrm{i} 4}}+e$

$\mathrm{CBD}_{\mathrm{a}}=\lambda_{05} \cdot X_{\mathrm{i} 5}^{\lambda_{\mathrm{i}}}+e$

$\mathrm{CBH}_{\mathrm{a}}=\lambda_{06} \cdot X_{\mathrm{i} 6}^{\lambda_{\mathrm{i}}}+e$

where $X_{i 1}-X_{i 6}$ are the potential independent variables $(N, G$, $\left.d_{q}, H_{m}, H_{0}, t\right) ; \lambda_{01}-\lambda_{06}$ and $\lambda_{i 1}-\lambda_{i 6}(i=1, \ldots, n)$ are the parameters to be estimated in the fitting process and $e$ is the error term. Note that no distinction was made between equations for effective and average CFL. Depending on whether effective or average CBD and $\mathrm{CBH}$ is considered by the end-user, Eqs. [5] or [8], respectively, should be selected for CFL estimation.

As there is no single, widely accepted, bulk density threshold for estimating $\mathrm{CBH}_{\mathrm{e}}$ (e.g. Alexander 2006), modelling the vertical profile of the $\mathrm{CBD}$ will allow $\mathrm{CBH}_{\mathrm{e}}$ to be estimated when the former reaches any specified minimum value. Preliminary analysis revealed that a three-parameter
Weibull distribution function best fit the data on the vertical profile:

$\mathrm{CBD}=\delta_{0}\left[1-\exp \left(-\left(\frac{H-0.3}{\delta_{1}}\right)^{\delta_{2}}\right)\right]+e$

where $\mathrm{CBD}$ is the canopy bulk density (kilogrammes per cubic metre); $H$ is the stand height above ground (metres); $\delta_{0}, \delta_{1}$ and $\delta_{2}$ are the parameters to be estimated and $e$ is the error term.

If model parameters in Eq. [11] (obtained for each plot) are related to stand variables, the vertical CBD distribution at stand level (and subsequently $\mathrm{CBD}_{\mathrm{e}}$ and $\mathrm{CBH}_{\mathrm{e}}$ ) can be easily estimated.

\subsection{Model fitting}

Model errors of the systems of Eqs. [1]-[2], [3]-[4], [5]-[7], and [8]-[10] are expected to be correlated, and therefore, simultaneous fitting must be carried out (e.g. Parresol 1999). Depending on whether the relationships between the dependent and the independent variables are homocedastic or heteroscedastic, the seemingly unrelated regression (SUR) or the generalized method of moments (GMM) must be used for this purpose. The GMM produces efficient parameter estimates under heteroscedastic conditions, without specifying the nature of the heteroscedasticity (SAS Institute Inc 2008). It also enables the correlated model errors to be dealt with. Both methods are available in the SAS/ETS ${ }^{\circledR}$ PROC MODEL procedure (SAS Institute Inc 2008).

The database used for fitting models [3] and [4] contains multiple observations of available fuel load components for each tree (i.e. hierarchical data), and so it is reasonable to expect autocorrelation within the residuals of each tree, which violates the assumption of independent error terms. Therefore, a simple autoregressive error structure $(\operatorname{AR}(x))$ was used in an attempt to correct the autocorrelation because the distance between biomass measurements is constant along the stem $(1 \mathrm{~m})$.

The best set of independent variables for the systems of Eqs. [5-7] and [8-10] was selected by using a logarithmic transformation of the original models and fitting each model separately. The stepwise variable selection method, in combination with an understanding of the modelled process (biological sense of the variables and the signs of the parameter estimates), was used. In addition, the presence of multicollinearity among variables was evaluated by the condition number (Belsley 1991).

Parameter estimates of Eq. [11] were obtained in a similar manner but by use of linear models. The Kolmogorov-Smirnov $(\mathrm{K}-\mathrm{S})$ test was used to verify whether the observed and predicted (by modelling parameters from stand variables) CBD values were drawn from the same distribution. A $5 \%$ significance level was selected both for assessing the significance of model parameter estimates and for the $\mathrm{K}-\mathrm{S}$ test. 
Evaluation of the performance of the models was based on numerical and graphical analysis. Graphical analysis was carried out by plotting the residuals against the predicted values and the observed values against the predicted values of the dependent variable. Numerical analysis was carried out by the goodness-of-fit statistics root mean squared error (RMSE) and coefficient of determination $\left(R^{2}\right)$. The RMSE provides a measure of the precision of the estimates in the same units as the dependent variable, while the coefficient of determination measures the amount of the observed variability explained by the model.

\section{Results}

The biomass equations developed for available crown fuel components $\left(w_{l}\right.$ and $\left.w_{b 6}\right)$ for both pine species are shown in Table 2. Parameter estimates were obtained by the GMM method. Diameter at breast height was the best predictor variable for both fuel components and species, and it explained more than $68 \%$ of the observed variability.

The parameter estimates for the two-parameter logistic Eqs. [3] and [4] are shown in Table 3. The SUR method was used for model fitting because the plots of cumulative dry weight of needles $\left(R w_{1}\right)$ and fine twigs $\left(R w_{b 6}\right)$ against $R h$ show homoscedasticity. Autocorrelation was corrected by modelling the error term with a first-order autoregressive error structure $(\mathrm{AR}(1))$. Figure 1 shows how the trend in residuals as a function of lag residuals within the same tree disappeared after the correction.

For maritime pine, the logistic model explained more than 92 and $88 \%$ of the variation in the vertical fuel profile for needles and fine twigs, respectively. These values were slightly lower for radiata pine, for which around $86 \%$ of the total variability was explained for both fuel components. Figure 2 shows the fitted curves superimposed on the observed data of cumulative dry weight for needles $\left(R w_{l}\right)$ and fine twigs $\left(R w_{b 6}\right)$ against $R h$. It should be noted that both $R h$ and $R w$ are calculated from the top of the tree.

Comparative minimum, maximum and mean values and standard deviations of CFL, $\mathrm{CBD}_{\mathrm{e}}, \mathrm{CBD}_{\mathrm{a}}, \mathrm{CBH}_{\mathrm{e}}$ and $\mathrm{CBH}_{\mathrm{a}}$ for each species are shown in Table 4. Comparison assumes that sampled plots are representative of the current young and highly stocked stands of the species in the region. The mean values of CFL were higher for $P$. radiata than for $P$. pinaster stands. Nevertheless, the mean values of both $\mathrm{CBD}_{\mathrm{e}}$ and $\mathrm{CBD}_{\mathrm{a}}$ were higher for maritime pine than for radiata pine stands. Moreover, the mean $\mathrm{CBD}_{\mathrm{e}}$ was around $20 \%$ lower than $\mathrm{CBD}_{\mathrm{a}}$ for both species. Canopy base height (defined either by $\mathrm{CBH}_{\mathrm{e}}$ or $\mathrm{CBH}_{\mathrm{a}}$ ) was substantially higher for radiata pine than for maritime pine stands. For both species, the mean $\mathrm{CBH}_{\mathrm{e}}$ was again around $25 \%$ lower than the mean $\mathrm{CBH}_{\mathrm{a}}$.

After selecting the best set of independent variables for each canopy fuel variable, the following allometric functions were obtained for maritime pine:

$\mathrm{CFL}=\lambda_{01} \cdot G^{\lambda_{11}}$

$\mathrm{CBD}_{\mathrm{e}}=\lambda_{02} \cdot G^{\lambda_{12}} \cdot H_{0}^{\lambda_{22}}$

$\mathrm{CBH}_{\mathrm{e}}=\lambda_{03} \cdot H_{m}^{\lambda_{13}}$

$\mathrm{CFL}=\lambda_{04} \cdot G^{\lambda_{14}}$

$\mathrm{CBD}_{\mathrm{a}}=\lambda_{05} \cdot G^{\lambda_{15}} \cdot N^{\lambda_{25}}$

$\mathrm{CBH}_{\mathrm{a}}=\lambda_{06} \cdot H_{m}^{\lambda_{16}}$

For radiata pine, the expressions are as follows:

$\mathrm{CFL}=\lambda_{01} \cdot G^{\lambda_{11}} \cdot N^{\lambda_{21}}$

$\mathrm{CBD}_{\mathrm{e}}=\lambda_{02} \cdot G^{\lambda_{12}} \cdot N^{\lambda_{22}} \cdot H_{0}^{\lambda_{32}}$

$\mathrm{CBH}_{\mathrm{e}}=\lambda_{03} \cdot H_{m}^{\lambda_{13}}$

$\mathrm{CFL}=\lambda_{04} \cdot G^{\lambda_{14}} \cdot N^{\lambda_{24}}$

$\mathrm{CBD}_{\mathrm{a}}=\lambda_{05} \cdot G^{\lambda_{15}} \cdot N^{\lambda_{25}}$

$\mathrm{CBH}_{\mathrm{a}}=\lambda_{06} \cdot H_{m}^{\lambda_{16}}$

These systems of equations were fitted simultaneously by the GMM method. The parameter estimates and the goodness-

Table 2 Biomass equations and goodness-of-fit statistics for available fuel components ( $w_{l}$ and $\left.w_{b 6}\right)$ of maritime and radiata pine

\begin{tabular}{|c|c|c|c|c|c|}
\hline \multicolumn{3}{|l|}{ P. pinaster } & \multicolumn{3}{|l|}{ P. radiata } \\
\hline Biomass equation & $R^{2}$ & RMSE (kg) & Biomass equation & $R^{2}$ & RMSE (kg) \\
\hline$w_{l}=0.01566 \cdot d^{2.072}$ & 0.837 & 4.77 & $w_{l}=0.02023 \cdot d^{1.899}$ & 0.697 & 2.83 \\
\hline$w_{b 6}=0.007241 \cdot d^{1.789}$ & 0.677 & 1.18 & $w_{b 6}=0.01605 \cdot d^{1.864}$ & 0.790 & 1.55 \\
\hline
\end{tabular}

$w_{l}$ and $w_{b 6}$ dry mass of needles and fine twigs, respectively $(\mathrm{kg}) ; d$ diameter at breast height (centimetres) 
Table 3 Parameter estimates and goodness-of-fit statistics for $R w_{l}$ and $R w_{b 6}$ equations

$R w_{l}$ and $R w_{b 6}$ ratio of the cumulative dry weight of each $1-\mathrm{m} \log$ to the total weight of needles and fine twigs, respectively; $\rho$ autocorrelation parameter of the AR (1) error structure

\begin{tabular}{|c|c|c|c|c|c|c|c|}
\hline \multirow[t]{2}{*}{ Fuel component } & \multirow[t]{2}{*}{ Parameter } & \multicolumn{3}{|c|}{ P. pinaster } & \multicolumn{3}{|l|}{ P. radiata } \\
\hline & & Estimate & $R^{2}$ & RMSE (kg) & Estimate & $R^{2}$ & RMSE (kg) \\
\hline \multirow[t]{3}{*}{ Needles $\left(R w_{l}\right)$} & $\beta_{0}$ & 2.987 & \multirow[t]{3}{*}{0.924} & \multirow[t]{3}{*}{0.109} & 2.710 & \multirow[t]{3}{*}{0.865} & \multirow[t]{3}{*}{0.142} \\
\hline & $\beta_{1}$ & 11.55 & & & 10.77 & & \\
\hline & $\rho$ & 0.7509 & & & 0.9025 & & \\
\hline \multirow[t]{3}{*}{ Twigs $<6 \mathrm{~mm}\left(R w_{b 6}\right)$} & $\beta_{0}$ & 3.642 & \multirow[t]{3}{*}{0.883} & \multirow[t]{3}{*}{0.140} & 3.369 & \multirow[t]{3}{*}{0.862} & \multirow[t]{3}{*}{0.146} \\
\hline & $\beta_{1}$ & 8.496 & & & 7.785 & & \\
\hline & $\rho$ & 0.7452 & & & 0.8698 & & \\
\hline
\end{tabular}

of-fit statics are shown in Table 5. The values of the condition numbers did not indicate problems of multicollinearity.

The CFL models accounted for a high percentage of the total variability for both species. Canopy bulk density models (including either $\mathrm{CBD}_{\mathrm{e}}$ or $\mathrm{CBD}_{\mathrm{a}}$ ) explained between 64 and $98 \%$ of the observed variability for both species, whereas the respective percentages varied between 83 and $96 \%$ for canopy base height. All equations provided a random pattern of studentized residuals around zero, with homogeneous variance and no detectable significant trends (Fig. 3).

The linear models (and their goodness-of-fit statistics) relating the parameters of the Weibull distribution function for CBD to stand variables are shown in Table 6 . The percentage of variability explained by the models varied between 58 and $99 \%$. In addition, the values of the condition numbers did not indicate any problems of multicollinearity. The $\mathrm{K}-\mathrm{S}$ test revealed that only 1 of the 83 distributions for maritime pine and 6 of the 363 distributions for radiata pine, estimated by the respective linear models, were rejected.

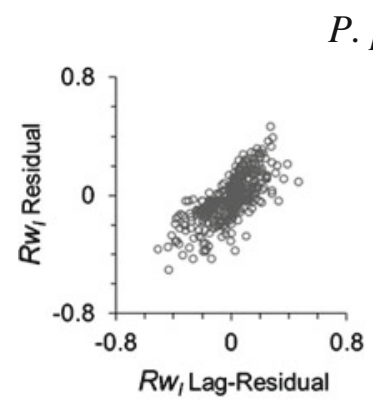

$P$. pinaster
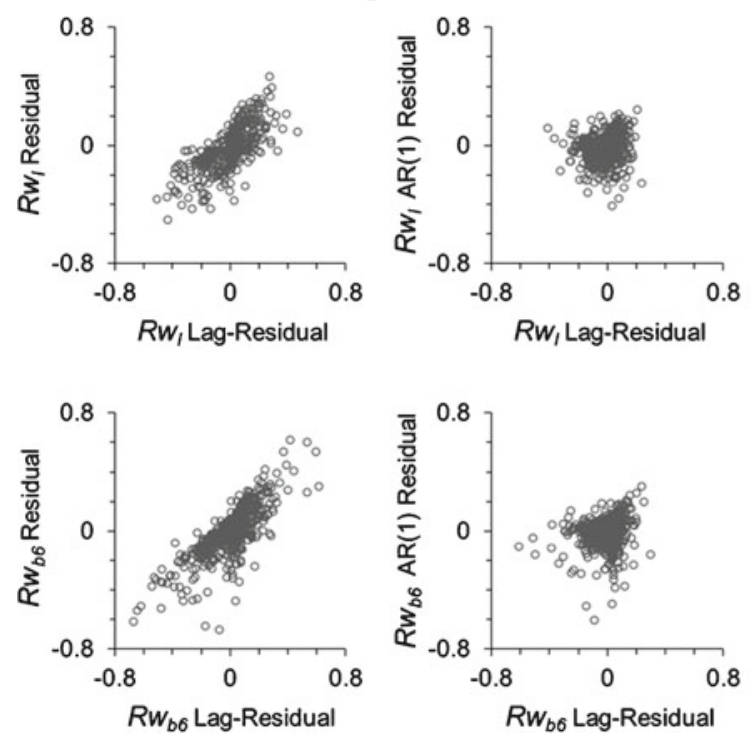

Fig. 1 Plots of residuals against lag residuals for the models of cumulative fuel estimation for needles $\left(R w_{l}\right)$ and fine twigs $\left(R w_{b 6}\right)$ fitted without considering the autocorrelation parameters (first and

\section{Discussion}

Diameter at breast height was the only reliable predictor of dry weight of needles and fine twigs for both maritime and radiata pines. Previous analysis (data not shown) indicated that use of the crown ratio $\left[\left(h-h_{b l c}\right) / h\right]$ could improve the predictions slightly. However, this variable was not used as it requires much greater sampling effort. Balboa-Murias et al. (2006) also found that $d$ was the only significant variable for estimating biomass of needles and twigs thinner than $0.5 \mathrm{~cm}$ for both species in the study region. Fernandes et al. (2002) also used $d$ to predict maritime pine needle biomass in Portugal.

According to the coefficient of determination, models [3] and [4] enable accurate estimation of the vertical distribution of available crown fuel. Similar percentages of variability have been explained in constructing vertical fuel profiles for maritime pine (Fernandes et al. 2002; Vega et al. 2009) and for other conifer species (Alexander et al. 2004; Mitsopoulos and Dimitrakopoulos 2007).

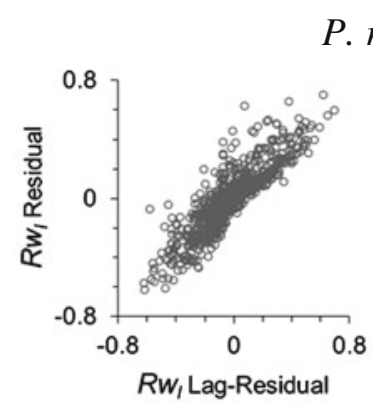

$P$. radiata
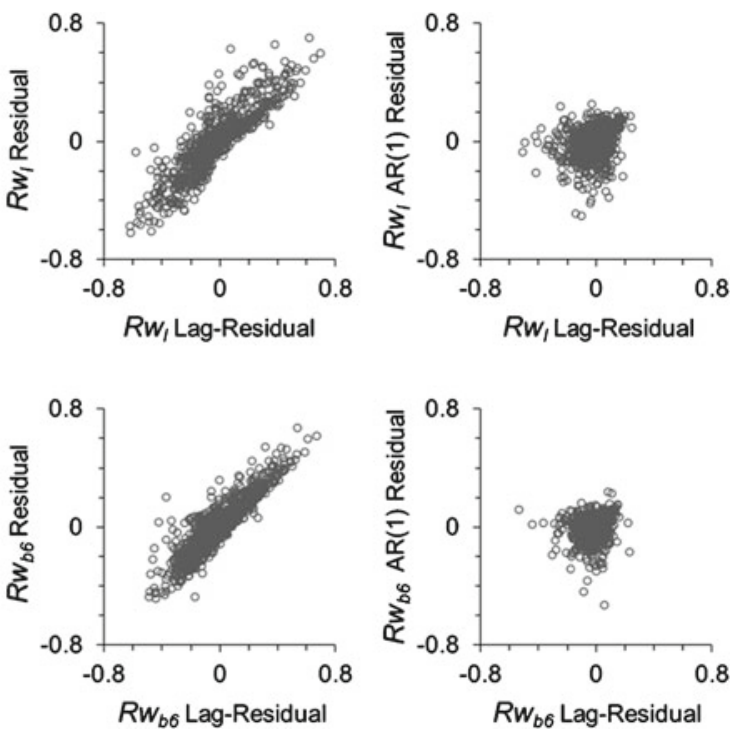

third columns) and using a first-order autoregressive error structure (second and fourth columns) 

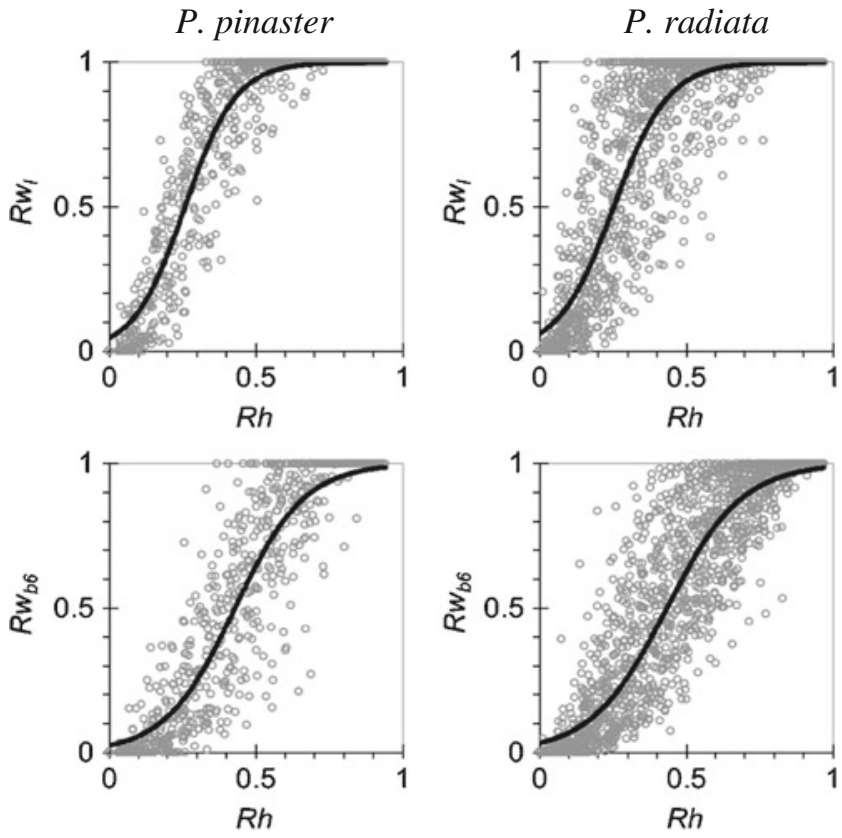

Fig. 2 Graphical representation of the models for cumulative fuel estimation of needles $\left(R w_{l}\right)$ and fine twigs $\left(R w_{b 6}\right)$ in relation to relative heights $(R h)$. Circles represent the observed values; solid lines represent the fitted model

In general, the vertical profiles of available canopy fuel were smooth, as expected because we are dealing with even-aged stands with simple vertical structure. As an example, Fig. 4 shows the vertical profile of the canopy fuel load for two comparable sampled plots of both species. The main difference is that in maritime pine most of the available fuel load is needles, whereas for radiata pine fine twigs are relatively more important. These results are consistent with the relative importance of both fuel components in total tree biomass for a tree of given diameter $d$ (see parameter estimates in Table 2).

The lower mean CBD values for radiata pine may be due to the low level of self-pruning of dead branches (Keeley and Zedler 1998) and to the higher stand heights (see Table 1). These two traits result in vertical distribution of CFL at a wider canopy depth, which decreases the weight of the canopy fuel per unit of volume. On the contrary, maritime pine is intermediate in terms of self-pruning (Keeley and Zedler 1998), and the height growth rate is lower. In addition, maritime pine usually grows in more highly stocked stands (see Table 1), which favours death and detachment of the lower canopy branches. Therefore, available canopy fuel is concentrated in a smaller portion of the tree crown, which increases the CBD.

There were substantial differences between average and effective CBD and CBH values for both species. $\mathrm{CBD}_{a}$ is estimated by dividing CFL by the live canopy depth (calculated as the difference between $H_{m}$ and $\mathrm{CBH}_{\mathrm{a}}$ ). According to this definition of $\mathrm{CBH}_{\mathrm{a}}$, the bottom of tree crowns (where branches are dead because of self-pruning) is not taken into account. Nevertheless, estimation of the vertical distribution of available crown fuel load considers the weight of dead fine twigs below $h_{b l c}$. These different assumptions result in mean average $\mathrm{CBD}$ and $\mathrm{CBH}$ values that are larger than the mean effective counterparts. Authors who have considered dead fine twigs along the stem in destructive sampling (e.g. Reindhart et al. 2006) also reported lower $\mathrm{CBD}_{e}$ and $\mathrm{CBH}_{\mathrm{e}}$ values than the $\mathrm{CBD}_{\mathrm{a}}$ and $\mathrm{CBH}_{\mathrm{a}}$ counterparts.

Irrespectively of the estimation method used, the mean CBD values for both species were higher than the threshold of $0.1 \mathrm{~kg} \mathrm{~m}^{-3}$ empirically deduced by Agee (1996) and subsequently confirmed by Cruz et al. (2005) as the approximate value necessary to support active crowning.

Quantitative knowledge about canopy fuels for both radiata and maritime pine stands has been quite deficient until present (Cruz 2011; Fernandes and Rigolot 2007). For maritime pine, the studies by Hevia et al. (2011) and Vega et al. (2009) are the only ones based on estimating vertical canopy fuel profiles from destructively sampled tree data in Spain, and substantially different mean $\mathrm{CBD}_{\mathrm{e}}$ and $\mathrm{CBH}_{\mathrm{e}}$ values were obtained for each.

In regard to radiata pine, the study by Ruiz-González and Álvarez-Gonzalez (2011) is the only one available for this species in Spain. The mean value of $\mathrm{CBD}_{\mathrm{e}}$ reported $(0.21$ $\mathrm{kg} \mathrm{m}^{-3}$ ) is substantially higher than that obtained in the present study $\left(0.10 \mathrm{~kg} \mathrm{~m}^{-3}\right)$. This discrepancy is mainly explained by the different methods used to estimate the

Table 4 Summarised data for the computed canopy fuel variables

\begin{tabular}{|c|c|c|c|c|c|c|c|c|}
\hline \multirow[t]{2}{*}{ Canopy fuel variable } & \multicolumn{4}{|c|}{ P. pinaster } & \multicolumn{4}{|c|}{ P. radiata } \\
\hline & Mean & Max. & Min. & SD & Mean & Max. & Min. & SD \\
\hline CFL & 0.896 & 1.96 & 0.229 & 0.319 & 1.19 & 2.59 & 0.530 & 0.289 \\
\hline $\mathrm{CBD}_{\mathrm{e}}$ & 0.139 & 0.308 & 0.0497 & 0.0388 & 0.103 & 0.197 & 0.0576 & 0.0231 \\
\hline $\mathrm{CBD}_{\mathrm{a}}$ & 0.176 & 0.365 & 0.0796 & 0.0632 & 0.129 & 0.236 & 0.0738 & 0.0294 \\
\hline $\mathrm{CBH}_{\mathrm{e}}$ & 3.86 & 7.50 & 1.20 & 1.31 & 7.37 & 13.50 & 1.80 & 2.59 \\
\hline $\mathrm{CBH}_{\mathrm{a}}$ & 5.36 & 13.14 & 1.84 & 2.29 & 9.78 & 21.13 & 2.83 & 4.01 \\
\hline
\end{tabular}

CFL canopy fuel load (kilogrammes per square metre), $C B D_{e}$ effective canopy bulk density (kilogrammes per cubic metre); $\mathrm{CBD}_{\mathrm{a}}$ average canopy bulk density (kilogrammes per cubic metre), $\mathrm{CBH}_{\mathrm{e}}$ effective canopy base height (metres), $\mathrm{CBH}_{\mathrm{a}}$ average canopy base height (metres) 
Table 5 Parameter estimates and goodness-of-fit statistics for the allometric models used to estimate the canopy fuel variables

\begin{tabular}{|c|c|c|c|c|c|c|c|c|c|c|}
\hline \multirow[t]{2}{*}{ Canopy fuel variable } & \multicolumn{5}{|l|}{ P. pinaster } & \multicolumn{5}{|l|}{ P. radiata } \\
\hline & Parameter & Estimate & $R^{2}$ & RMSE & Condition number & Parameter & Estimate & $R^{2}$ & RMSE & Condition number \\
\hline \multirow[t]{2}{*}{ CFL } & $\begin{array}{l}\lambda_{01} \\
\lambda_{11}\end{array}$ & $\begin{array}{l}0.02817 \\
1.013\end{array}$ & 0.997 & 0.0184 & 22.3 & $\begin{array}{l}\lambda_{01} \\
\lambda_{11}\end{array}$ & $\begin{array}{l}0.02862 \\
0.9367\end{array}$ & 0.991 & 0.0277 & 47.9 \\
\hline & & & & & & $\lambda_{21}$ & 0.04685 & & & \\
\hline \multirow[t]{3}{*}{$\mathrm{CBD}_{\mathrm{e}}$} & $\begin{array}{l}\lambda_{02} \\
\lambda_{12}\end{array}$ & $\begin{array}{l}0.01976 \\
1.004\end{array}$ & 0.981 & 0.00537 & 33.3 & $\begin{array}{l}\lambda_{02} \\
\lambda_{12}\end{array}$ & $\begin{array}{l}0.05513 \\
0.9494\end{array}$ & 0.944 & 0.00545 & 94.6 \\
\hline & $\lambda_{22}$ & -0.5851 & & & & $\lambda_{22}$ & 0.02968 & & & \\
\hline & & & & & & $\lambda_{32}$ & -0.9780 & & & \\
\hline \multirow[t]{2}{*}{$\mathrm{CBH}_{\mathrm{e}}$} & $\lambda_{03}$ & 0.2037 & 0.890 & 0.440 & 21.2 & $\lambda_{03}$ & 0.1641 & 0.907 & 0.793 & 26.8 \\
\hline & $\lambda_{13}$ & 1.243 & & & & $\lambda_{13}$ & 1.275 & & & \\
\hline \multirow[t]{3}{*}{ CFL } & $\lambda_{04}$ & 0.02798 & 0.997 & 0.0182 & 22.3 & $\lambda_{04}$ & 0.02706 & 0.991 & 0.0275 & 47.9 \\
\hline & $\lambda_{14}$ & 1.014 & & & & $\lambda_{14}$ & 0.9449 & & & \\
\hline & & & & & & $\lambda_{24}$ & 0.0509 & & & \\
\hline \multirow[t]{3}{*}{$\mathrm{CBD}_{\mathrm{a}}$} & $\lambda_{05}$ & 0.004207 & 0.614 & 0.0397 & 59.0 & $\lambda_{05}$ & 0.001106 & 0.928 & 0.00791 & 48.3 \\
\hline & $\lambda_{15}$ & 0.7333 & & & & $\lambda_{15}$ & 0.7479 & & & \\
\hline & $\lambda_{25}$ & 0.1751 & & & & $\lambda_{25}$ & 0.3015 & & & \\
\hline \multirow[t]{2}{*}{$\mathrm{CBH}_{\mathrm{a}}$} & $\lambda_{06}$ & 0.1213 & 0.830 & 0.944 & 22.2 & $\lambda_{06}$ & 0.09679 & 0.960 & 0.804 & 28.5 \\
\hline & $\lambda_{16}$ & 1.596 & & & & $\lambda_{16}$ & 1.536 & & & \\
\hline
\end{tabular}

Canopy fuel variables are defined in Table 4

vertical distribution of available crown fuel load. RuizGonzález and Álvarez-Gonzalez (2011) assumed that the available fuel load is vertically distributed according to the

$$
\text { P. pinaster }
$$

Effective variables
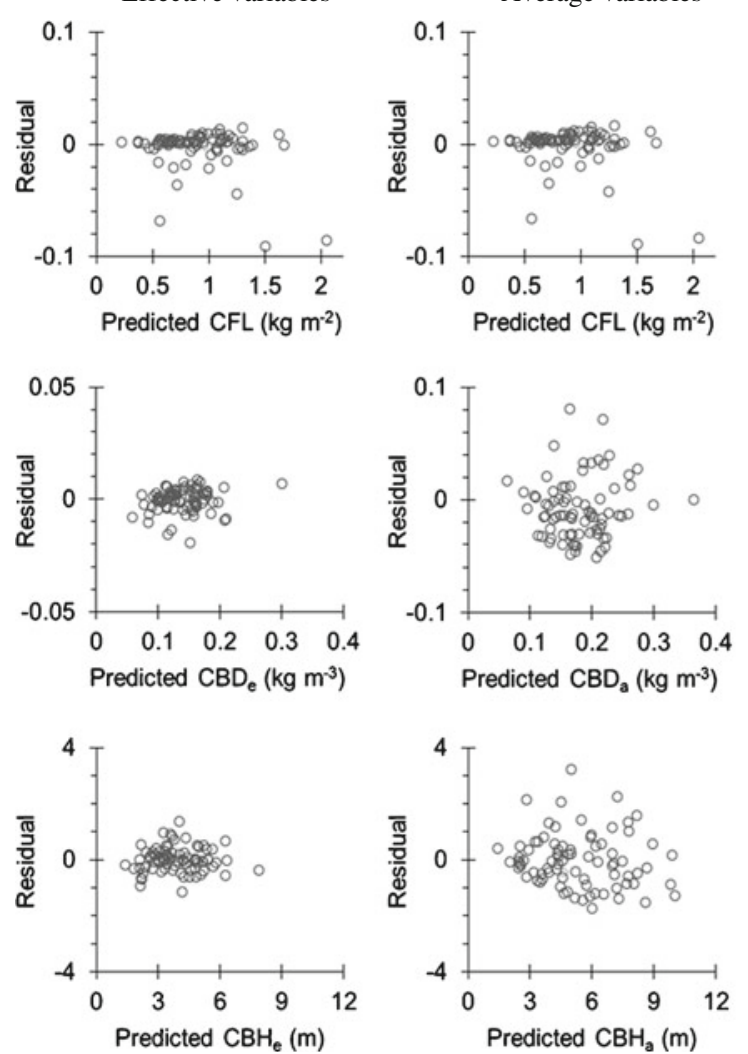

vertical distribution of the live crown volume, which was in turn estimated by use of a crown profile model (CrecenteCampo 2008). This crown profile model does not consider the

\section{P. radiata}

Effective variables

Average variables
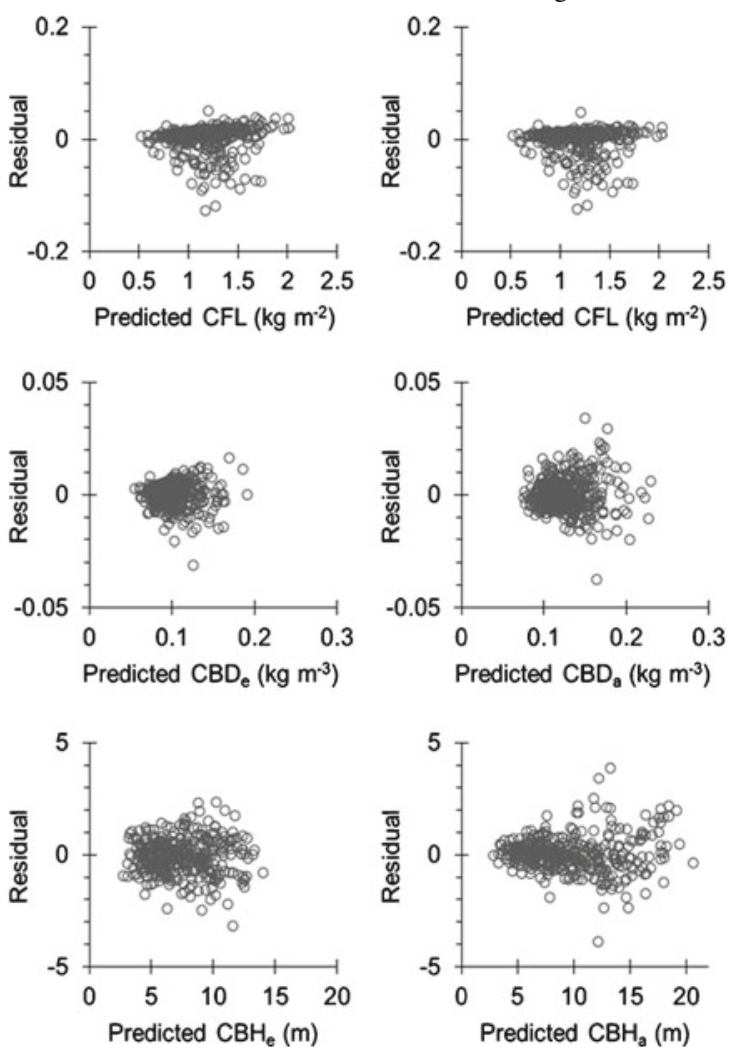

Fig. 3 Plots of residuals against predicted values of CFL, CBD and CBH for maritime pine and radiata pine 
Table 6 Parameter estimates and goodness-of-fit statistics for the models relating parameters of the Weibull distribution function to stand variables

$G$ stand basal area (square metres per hectare); $H_{0}$ dominant height (metres), $d_{q}$ quadratic mean diameter (centimetres)

\begin{tabular}{lllll}
\hline Species & Equation & $R^{2}$ & RMSE & Condition number \\
\hline P. pinaster & $\delta_{0}=0.203+0.0935 \cdot G$ & 0.988 & 0.109 & 5.85 \\
& $\delta_{1}=0.429+0.642 \cdot H_{0}$ & 0.935 & 0.528 & 8.06 \\
& $\delta_{2}=1.01+0.0888 \cdot H_{0}+0.0612 \cdot d_{q}$ & 0.739 & 0.274 & 16.6 \\
P. radiata & $\delta_{o}=0.338+0.0965 \cdot G$ & 0.979 & 0.141 & 7.76 \\
& $\delta_{1}=-2.09+0.756 \cdot H_{0}$ & 0.985 & 0.449 & 8.59 \\
& $\delta_{2}=2.47+0.0117 \cdot H_{0}+0.0142 \cdot d_{q}$ & 0.585 & 0.139 & 17.9 \\
\hline
\end{tabular}

volume occupied by dead available fuel load, and therefore, it overestimates the $\mathrm{CBD}_{\mathrm{e}}$ values. The approach used in the present study is based on observed fuel distribution data from destructively sampled trees, and therefore, it provides a more realistic depiction of the vertical distribution of crown fuel (and in turn, of $\mathrm{CBD}_{\mathrm{e}}$ and $\mathrm{CBH}_{\mathrm{e}}$ ).

Therefore, the present results highlight the importance of considering the fuel load from dead fine twigs located below $h_{\text {blc }}$ in estimating $\mathrm{CBD}_{\mathrm{e}}$ and $\mathrm{CBH}_{\mathrm{e}}$. This is particularly important in maritime and radiata pine stands, in which dead fine twigs in the lower canopy may comprise substantial quantities of fuel (Cruz 2011; Fernandes and Rigolot 2007).

The mean $\mathrm{CBH}$ values (assessed either by average or effective values) obtained in this study suggest that maritime pine stands have a greater potential for crown initiation than radiata pine stands. In addition, if the critical intensity of surface fire for crowning is attained, crown fire spread is more likely in maritime pine stands because of the higher mean CBD values. This may partly explain why the burned area of this species is higher than would be expected from the degree of land cover (Fernandes and Rigolot 2007).

The allometric equations developed show that CFL was positively correlated with stand density (especially with $G$ ) for both pine species and both estimation alternatives. This supports previous findings that $G$ is the most important variable when predicting dry weight of biomass components at stand level (e.g. Castedo-Dorado et al. 2012; Mitsopoulos and Dimitrakopoulos 2007).
Stand density (given by both $G$ and $N$ ) and $H_{0}$ were the best independent variables for modelling both $\mathrm{CBD}_{\mathrm{e}}$ and $\mathrm{CBD}_{\mathrm{a}}$. Cruz et al. (2003) and Mitsopoulos and Dimitrakopoulos (2007) also found that CBD depended greatly on $N$ and $G$ but not on stand height. Nevertheless, Ruiz-González and Álvarez-Gonzalez (2011) found that $H_{0}$ was significantly and inversely related to both $\mathrm{CBD}_{\mathrm{a}}$ and $\mathrm{CBD}_{\mathrm{e}}$. The negative value of the parameter estimates for $H_{0}$ can be explained by the fact that a higher stand dominant height will cause the available fuel load to be distributed over a larger crown length, thus decreasing the mass per unit volume.

As expected, stand height had the greatest effect on both $\mathrm{CBH}_{\mathrm{a}}$ and $\mathrm{CBH}_{\mathrm{e}}$ for both species. Stand density showed only a marginally positive effect, and therefore, it was not considered. Both $H_{m}$ and $H_{0}$ are closely and positively related to $\mathrm{CBH}$ variables and can be used for modelling. $H_{m}$ was finally selected because it is more amenable to management, which ensures that $\mathrm{CBH}$ will increase after thinning from below (the most usual thinning option for these species in the region) (Cruz et al. 2003, 2010).

Parameterization of the Weibull distribution function developed will allow the vertical distribution of available fuel load to be determined from easily measured stand attributes (Keyser and Smith 2010). Subsequently, $\mathrm{CBH}_{\mathrm{e}}$ can be estimated for any desired bulk density threshold by solving Eq. [11] once parameterized with the models shown in Table 6. In the same way, $\mathrm{CBD}_{\mathrm{e}}$ can also be estimated by deriving Eq. [11] with respect to $H$. The systems of parameter prediction
Fig. 4 Comparative example of vertical canopy fuel load distribution in one sampled plot of maritime pine (left) and radiata pine $(r i g h t)$. The values of $H_{0}$ (11.8 $\mathrm{m}$ for maritime pine and $13 \mathrm{~m}$ for radiata pine) and $N(1,600$ trees per hectare $)$ are similar for both plots
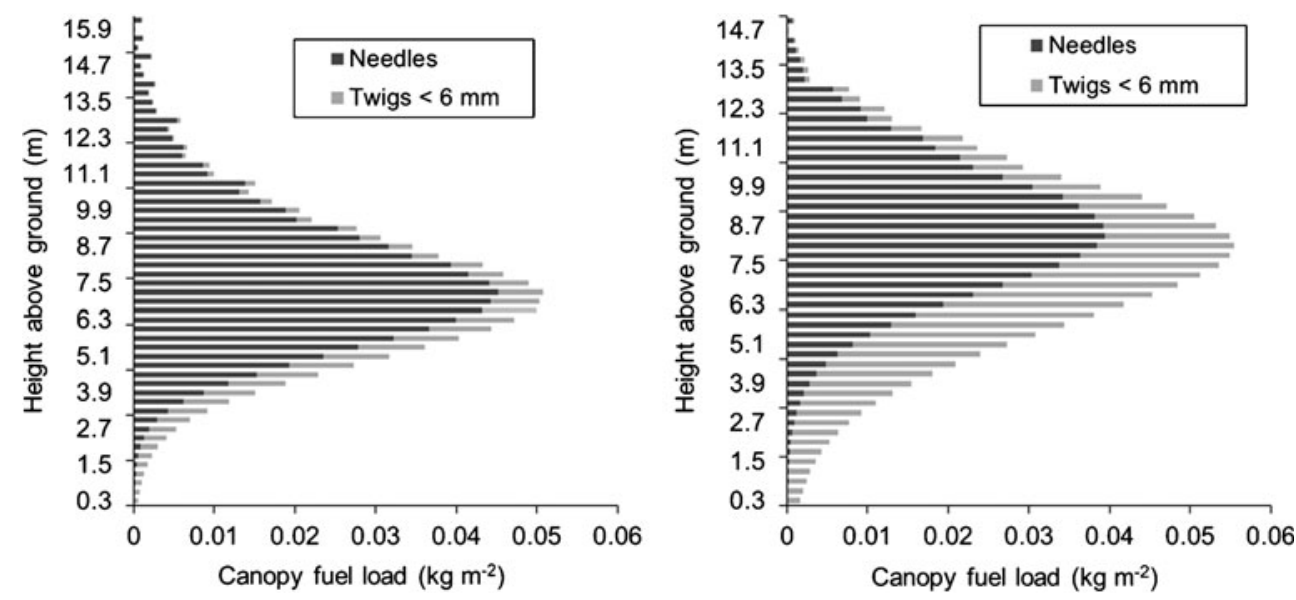
models developed provide logical results for both canopy fuel variables: (1) an increase in $G$ or $d_{q}$ has a positive impact on $\mathrm{CBD}_{\mathrm{e}}$ values, but an almost negligible impact on $\mathrm{CBH}_{\mathrm{e}}$, and (2) for the same $G$ and $d_{q}$ values, increasing $H_{0}$ implies smaller $\mathrm{CBD}_{\mathrm{e}}$ and larger $\mathrm{CBH}_{\mathrm{e}}$ values.

When combined with fire behaviour models and simulation systems, the prediction equations presented are useful for establishing fuel treatment priorities and evaluating the effectiveness of fuel management activities. For these purposes, adequate information about canopy fuel metrics (mainly CBD and $\mathrm{CBH}$ ) is necessary. The present results highlight that the method of distributing available fuel within the crown may have a substantial impact on estimating $\mathrm{CBD}$ and $\mathrm{CBH}$, which in turn may affect the effectiveness of planning fuel treatments (Agca et al. 2011; Hall and Burke 2006; Keyser and Smith 2010).

As already pointed out, estimations of $\mathrm{CBD}_{\mathrm{a}}$ and $\mathrm{CBH}_{\mathrm{a}}$ are compatible with the canopy fuel stratum characteristics used in Van Wagner's (1977) model, whereas the estimations of $\mathrm{CBD}_{\mathrm{e}}$ and $\mathrm{CBH}_{\mathrm{e}}$ depart from the input specifications of this model. Therefore, although modelling the vertical profile of available canopy fuel (including dead fine twigs below $h_{b l c}$ ) provides a realistic vertical fuel profile depiction, these fuels introduce an error term in the model of Van Wagner because "their contribution to a heat balance calculation is quite distinct from live fuels" (Cruz et al. 2004). It must be taken into account that Van Wagner's crown fire initiation and propagation model is widely used and has been implemented in most fire modelling systems (BehavePlus, FARSITE, FlamMap, etc.).

\section{Conclusions}

In this study, the vertical profile of available canopy fuel for maritime and radiata pine stands in NW Spain was modelled with data from 185 destructively sampled trees. This modelling approach provided a realistic depiction of the vertical fuel distribution, considering both the fuels in the live crown and the dead fine twigs located below the live crown base height. The canopy bulk density and canopy base height values estimated from the developed models differs substantially from those obtained by considering a uniform distribution throughout the entire length of the live crown or even a distribution proportional to live crown volume.

Canopy fuels for both pine species are characterized by a relatively low $\mathrm{CBH}$ (which results in high probability of crown fire initiation) and a higher CBD than the threshold widely accepted for crown fire propagation $\left(0.1 \mathrm{~kg} \mathrm{~m}^{-3}\right)$. Moreover, assuming the same surface fuel complex characteristics, crowning is more likely in maritime pine than in radiata pine stands, since lower $\mathrm{CBH}$ and higher $\mathrm{CBD}$ values were obtained for the sampled plots.
The allometric models developed for estimating canopy fuel metrics provide a reasonable estimation of canopy fuel structure, since they explain a high percentage of the observed variability. In addition, they can be estimated from common stand descriptors, and therefore, a low degree of sampling effort is required. Future evaluation of the regression models with real independent data will allow assessment of their reliability.

Acknowledgments The authors are grateful to two anonymous reviewers whose comments substantially improved an earlier version of this manuscript.

Funding Funding for this research was provided by the Spanish Ministry of Science and Innovation, project No. AGL2008-02259/ FOR.

\section{References}

Agca M, Popescu SC, Harper CW (2011) Deriving forest canopy fuel parameters for loblolly pine forests in eastern Texas. Can J For Res 41:1618-1625

Agee JK (1996) The influence of forest structure on fire behaviour. In: Cooper SL (ed) Proceedings of the 17th annual forest vegetation management conference, Shasta County Cooperative Extension, University of California, pp 52-68, Redding (California)

Alexander ME (2006) Models for predicting crown fire behavior - a review. In: V Short course on fire behaviour, Association for the Development of Industrial Aerodynamics, Forest Fire Research Centre, Coimbra (Portugal)

Alexander ME, Cruz MG (2011) Crown fire dynamics in conifer forests. In: Synthesis of knowledge of extreme fire behavior: volume I for fire managers. USDA Forest Service Gen. Tech. Rep. PNW-GTR-854, pp 107-142, Portland (Oregon)

Alexander ME, Stefner CN, Mason JA, Stocks BJ, Hartley GR, Maffey ME, Wotton BM, Taylor SW, Lavoie N, Dalrymple GN (2004) Characterizing the jack pine-black spruce fuel complex of the International Crown Fire Modelling Experiment (ICFME). Canadian Forest Service Information Report NOR-X-393. Northern Forestry Centre, Edmonton

Balboa-Murias MA, Rodríguez-Soalleiro R, Merino A, ÁlvarezGonzález JG (2006) Temporal variations and distribution of carbon stocks in aboveground biomass of radiata pine and maritime pine pure stands under different silvicultural alternatives. For Ecol Manage 237:29-38

Belsley DA (1991) Conditioning diagnostics: collinearity and weak data in regression. Wiley, New York

Call PT, Albini FA (1997) Aerial and surface fuel consumption in crown fires. Int J Wildland Fire 7:259-264

Castedo-Dorado F, Diéguez-Aranda U, Barrio-Anta M, SánchezRodríguez M, von Gadow K (2006) A generalized heightdiameter model including random components for radiata pine plantations in northwestern Spain. For Ecol Manage 229:202-213

Castedo-Dorado F, Gómez-García E, Diéguez-Aranda U, Barrio-Anta M, Crecente-Campo F (2012) Aboveground stand-level biomass estimation: a comparison of two methods for major forest species in northwest Spain. Ann For Sci 69:735-746

Crecente-Campo F (2008) Modelo de crecimiento de árbol individual para Pinus radiata D. Don. en Galicia. Ph D thesis, University of Santiago de Compostela 
Cruz MG (2011) Fuels and fire behaviour potential associated with FMZ. CSIRO Ecosystem Sciences. Report prepared for ForestrySA, Canberra

Cruz MG, Alexander ME (2010) Assessing crown fire potential in coniferous forest of western North America: a critique of current approaches and recent simulation studies. Int $\mathrm{J}$ Wildland Fire 19:377-398

Cruz MG, Alexander ME (2012) Evaluating regression model estimates of canopy fuel stratum characteristics in four crown fire-prone fuel types in western North America. Int J Wildland Fire 21:168-179

Cruz MG, Alexander ME, Wakimoto RH (2003) Assessing canopy fuel stratum characteristics in crown fire prone fuel types of western North America. Int J Wildland Fire 12:39-50

Cruz MG, Alexander ME, Wakimoto RH (2004) Modeling the likelihood of crown fire occurrence in conifer forest stands. For Sci 50:640-658

Cruz MG, Alexander ME, Wakimoto RH (2005) Development and testing of models for predicting crown fire rate of spread in conifer forest stands. Can J For Res 35:1626-1639

Cruz MG, Alexander ME, Wakimoto RH (2010) Comment on "Estimating canopy fuel characteristics in five conifer stands in the western United States using tree and stand measurements". Can J For Res 40:2262-2263

Diéguez-Aranda U, Rojo A, Castedo-Dorado F, Álvarez JG, Barrio-Anta M, Crecente-Campo F, González JM, Pérez-Cruzado C, Rodríguez R, López-Sánchez CA, Balboa-Murias MA, Gorgoso JJ, Sánchez F (2009) Herramientas selvícolas para la gestión forestal sostenible en Galicia. Consellería do Medio Rural, Xunta de Galicia, Santiago de Compostela

Fernandes PM, Rigolot E (2007) The fire ecology and management of maritime pine (Pinus pinaster Ait.). For Ecol Manage 241:1-13

Fernandes PM, Loureiro CA, Botelho HS, Ferreira A, Fernandes M (2002) Avaliaçao indirecta da carga de combustível em pinhal bravo. Silva Lusit 10:73-90

Hall SA, Burke IC (2006) Considerations for characterizing fuels as inputs for fire behaviour models. For Ecol Manage 227:102-114

Hevia A, Crabiffosse A, Majada J, Álvarez-González JG, Ruiz-González AD (2011) Modelo de distribución de la carga de combustibles finos en el dosel de copas de rodales regulares de Pinus pinaster: efecto de claras combinadas con podas. In: III Reunión del grupo de trabajo de modelización forestal de la SECF, Lugo (Spain)

Keane RE, Reinhardt ED, Scott J, Gray K, Reardon J (2005) Estimating forest canopy bulk density using six indirect methods. Can J For Res 35:724-739

Keeley JE, Zedler PH (1998) Evolution of life histories in Pinus. In: Richardson DM (ed) Ecology and biogeography of Pinus. Cambridge University Press, Cambridge, pp 219-250
Keyes CR, O'Hara KL (2002) Quantifying stand targets for silvicultural prevention of crown fires. West J Appl For 17:101-109

Keyser T, Smith FW (2010) Influence of crown biomass estimators and distribution on canopy fuel characteristics in ponderosa pine stands of the Black Hills. For Sci 56:156-165

Mitsopoulos ID, Dimitrakopoulos AD (2007) Canopy fuel characteristics and potential crown fire behaviour in Aleppo pine (Pinus halepensis Mill.) forests. Ann For Sci 64:287-299

MMA (2006) Los incendios forestales en España. Decenio 1996-2005. Ministerio de Medio Ambiente, Madrid

Parresol BR (1999) Assessing tree and stand biomass: a review with examples and critical comparisons. For Sci 45:573-593

Reeves MC, Ryan KC, Rollins MG, Thompson TG (2009) Spatial fuel data products of the LANDFIRE Project. Int J Wildland Fire 18:250-267

Reinhardt E, Scott J, Gray K, Keane R (2006) Estimating canopy fuel characteristics in five conifer stands in the western United States using tree and stand measurements. Can J For Res 36:2803-2814

Ruiz-González AD, Álvarez-González JG (2011) Canopy bulk density and canopy base height equations for assessing crown fire hazard in Pinus radiata plantations. Can J For Res 41:839-850

Sando RW, Wick CH (1972) A method of evaluating crown fuels in forest stands. USDA Forest Service Res Pap NC-84

SAS Institute Inc (2008) SAS/ETS ${ }^{\circledR} 9.2$ user's guide. SAS Institute Inc, Cary

Scott JH, Reinhardt ED (2001) Assessing crown fire potential by linking models of surface and crown fire behaviour. USDA Forest Service Res Pap RMRS-RP-29

Stocks BJ, Alexander ME, Wotton BM, Stefner CN, Flannigan MD, Taylor SW, Lavoie N, Mason JA, Hartley GR, Maffey ME, Dalrymple GN, Blake TW, Cruz MG, Lanoville RA (2004) Crown fire behaviour in a northern jack pine-black spruce forest. Can J For Res 34:1548-1560

Van Wagner CE (1977) Conditions for the start and spread of a crown fire. Can J For Res 7:23-34

Vega JA, Rey E, Ruiz Pérez I, Jiménez E, Pérez Suárez JR (2009) Estudio de tratamientos preventivos de incendios sobre la estructura del complejo integral de combustible forestal en masas de Pinus pinaster Ait. de Castilla y León. In: V Congreso Forestal Español, Ávila (Spain)

Williams DF (1978) Fuel properties before and after thinning in young radiata pine plantations. Fire Management Branch, Department of Conservation and Environment, Research Report NO. 3, Victoria

Xunta de Galicia (2001) O monte galego en cifras. Consellería de Medio Ambiente, Xunta de Galicia, Santiago de Compostela 